\title{
HIDROGEOQUÍMICA DE AQUÍFEROS FRATURADOS: ESTUDO DE CASO NA BACIA HIDROGRÁFICA DO RIO SÃO DOMINGOS, NOROESTE DO ESTADO DO RIO DE JANEIRO
}

\author{
Hydrogeochemistry of Fractured Aquifers: Case Study in the Rio São Domingos Watershed, \\ Rio de Janeiro, Brazil \\ Juliana Magalhães Menezes ${ }^{1}$, Gerson Cardoso da Silva $\mathrm{Jr}^{2}$. e Rodrigo Tavares dos Santos ${ }^{3}$
}

\begin{abstract}
RESUMO: $\quad$ As águas subterrâneas tornaram-se uma alternativa regional para o abastecimento doméstico e para a agricultura na Bacia Hidrográfica do Rio São Domingos - NW do RJ, já que os períodos de estiagem são normais na região. O objetivo do trabalho consiste na caracterização do comportamento hidrogeoquímico das águas subterrâneas que, cotejadas com as unidades litoestratigráficas da área, permitiram, de modo tentativo, estabelecer relações entre aquelas litologias e as assinaturas hidrogeoquímicas presentes. Realizaram-se investigações de campo e amostragens de água em 65 pontos da bacia. Depois das amostras serem analisadas em laboratório, os resultados foram classificados quanto ao tipo hidroquímico e tratados estatisticamente pelo método hierárquico de cluster. Os resultados indicam que as águas são, predominantemente, bicarbonatadas-mistas com tendência a bicarbonatadas-sódicas. As águas do aquífero raso apresentaram a maior variedade de tipos hidroquímicos, por influência do tipo de solo e de processos que dependem da vegetação, clima e influência antrópica, mas a maioria das amostras classificou-se como bicarbonatada-sódica ou bicarbonatada-mista. Nas águas profundas, a presença de $\mathrm{Ca}^{+2}$ e $\mathrm{Mg}^{+2}$ em maior quantidade ocorre de modo bastante evidente, o que deve refletir maior tempo de contato da água subterrânea percolante com materiais rochosos de caráter petrográfico mais básico, como os anfibolitos e rochas ígneas com caráter intermediário (como por exemplo, a composição granodiorítica da Unidade Leucocharnoquito). Não foi possível estabelecer de modo inequívoco relações consistentes entre o caráter hidrogeoquímico e as litologias presentes, o que se atribui às características do aquífero (fraturado, pouca profundidade) e do meio físico.
\end{abstract}

Palavras-chave: hidrogeoquímica, rochas cristalinas, análise de cluster, Noroeste do Rio de Janeiro.

ABSTRACT: Groundwater has become a local alternative for domestic and agricultural use in the São Domingos River Hydrographic Basin - located in the NW region of Rio de Janeiro State, Brazil, given that periods of drought are common in the region and surface water resources are scarce. The objective of the work consists on the hydrogeochemical characterization of groundwater which, when compared to the lithostratigraphic units of the area, has permitted, tentatively, to establish the relations between those lithotypes and hydrochemical signatures. Field surveys with water sampling were undertaken in 65 points of the basin. The samples were analyzed in laboratory under 44 parameters and classified according to the hydrochemical type and, later on, this information was treated statistically with the hierarchic cluster method. Results indicate that the groundwater is, predominantly, of mixed-bicarbonate facies, with a trend to sodium-bicarbonate. Shallow aquifer water presented great hydrochemical variety, due to influence of soil type and processes that are influenced or conditioned by vegetation, climate and human intervention. Most shallow water samples, though, were classified as sodium-bicarbonate or mixed-bicarbonate type. In deep waters, more signifcant amounts of $\mathrm{Ca}^{+2}$ and $\mathrm{Mg}^{+2}$ occur, a fact that must reflect a lengthier time of contact of percolating groundwater with basic petrographically rock materials, such as amphibolites and igneous rocks with intermediate character (as for example, the granodioritic composition of the Leucocharnockite Unit). It was not possible, nevertheless, to establish unequivocally consistent relations between the hydrogeochemical character and the existing rock types, due to the characteristics of the local aquifer (fractured, shallow) and the environment.

Keywords: hydrogeochemistry, fractured aquifer, cluster analysis, Northwest of Rio de Janeiro State.

\section{INTRODUÇÃO}

Grande parte do território brasileiro está assentada sobre os terrenos cristalinos. Muitas vezes, são nessas rochas que se encontram os únicos recursos hídricos com possibilidade de utilização. Rigorosos períodos de seca, por vezes associados à grande densidade populacional ou à utilização inadequada do solo para agricultura ao longo de séculos, tornam insuficientes as águas superficiais em muitas dessas áreas (LADEIRA, 1985).

O presente estudo foi desenvolvido na área da Bacia Hidrográfica do Rio São Domingos (BHRSD). Este rio é afluente do Rio Muriaé, pertencente ao Complexo Hidrográfico do Rio Paraíba do Sul. Compreende a totalidade do município de São José de Ubá e pequena porção do município de Itaperuna, no Noroeste do Estado do Rio de Janeiro (figura 1). O estudo integrou o projeto "Planejamento Conservacionista das Terras Visando a Recarga do Sistema Hídrico em Bacias Hidrográficas sobre o Embasamento Cristalino" (PRODETAB/EMBRAPA), que buscou proporcionar diretrizes para a otimização da recarga do sistema hídrico da BHRSD, através do planejamento integrado do uso e melhor manejo dos recursos naturais.

$\mathrm{O}$ presente estudo teve como objetivo

1(menezesgeo@yahoo.com.br)²(gerson@acd.ufrj.br.)ㄱ(boxrts@yahoo.com.br) 
principal a caracterização do comportamento hidrogeoquímico das águas subterrâneas e superficiais tendo em conta a sua inserção nas unidades litoestratigráficas definidas na área, que fornecem os materiais que constituem a massa de solutos presentes na água. Assim, buscouse estabelecer algumas relações entre as citadas litologias e as assinaturas hidrogeoquímicas. $\mathrm{O}$ trabalho incluiu, para alcançar esse objetivo, a realização de uma caracterização hidrogeoquímica na BHRSD, no contexto da ocorrência de materiais cristalinos como substrato geológico. Com este artigo pretende-se contribuir para o entendimento dos mecanismos que regem a interação entre as águas subterrâneas e o substrato cristalino fraturado nas condições encontradas na área de trabalho. Vastas regiões do Brasil são constituídas por essas rochas, encontradas mormente nos terrenos do Sudeste brasileiro e a compreensão da hidrogeologia destes terrenos é ainda muito escassa.

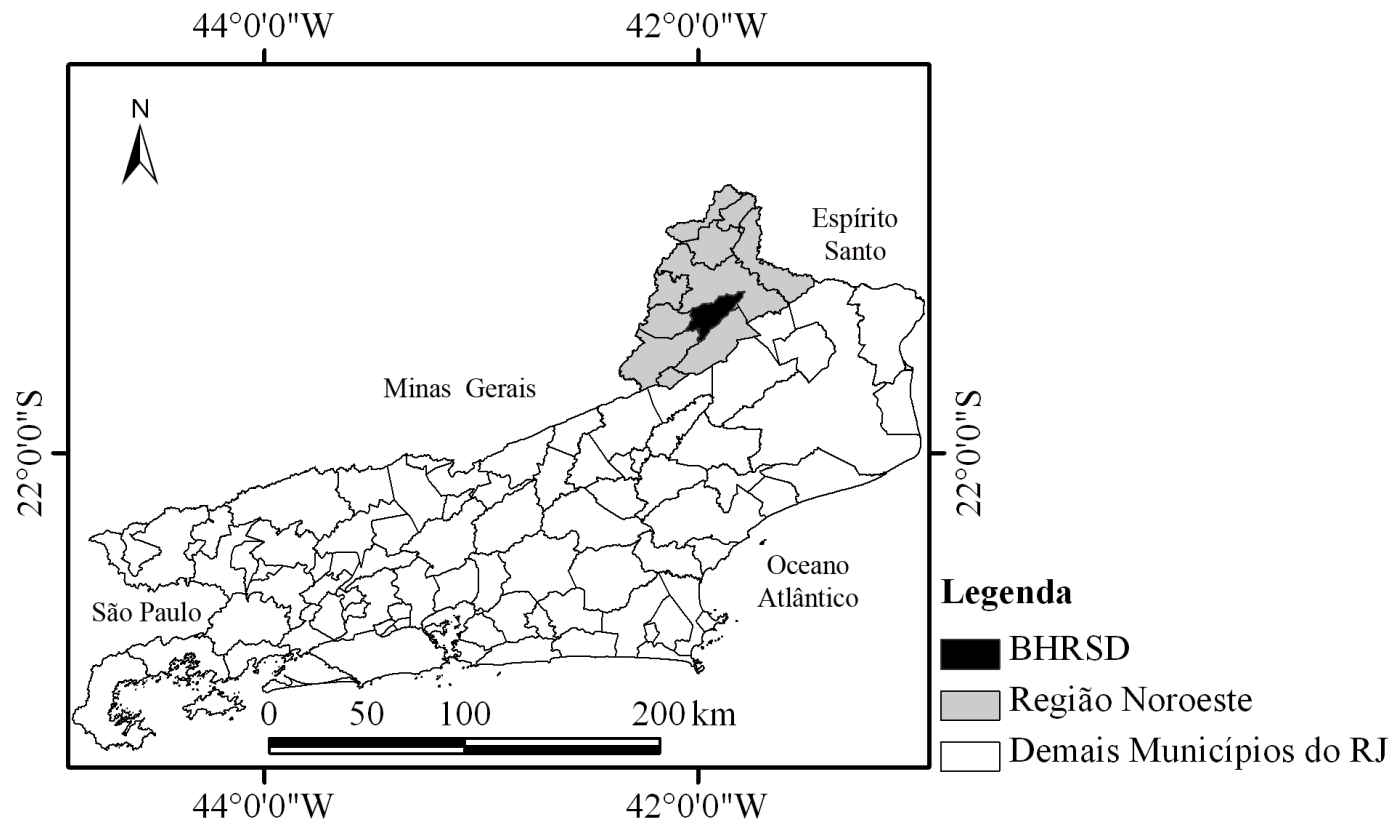

Figura 1: Localização da Bacia Hidrográfica do Rio São Domingos (BHRSD), São José de Ubá, Rio de Janeiro, Brasil.

Até o início da década de 1980, havia poucos estudos publicados sobre a ocorrência de água subterrânea em terrenos cristalinos fora do semi-árido do Nordeste Brasileiro (BERTACHINI, 1987). Desse período em diante, muitos estudos vêm sendo realizados, inclusive no Sudeste do país, mas, ainda hoje, há muito para ser compreendido sobre a hidrogeologia do Cristalino. Tal situação também ocorre em nível mundial, já que apenas muito recentemente estudos hidrogeológicos aprofundados dos aquíferos cristalinos fraturados vêm sendo realizados (TAYLOR e HOWARD, 1999; MORRIS et al., 2003; TRÖGER et al., 2003; NEVES e ALBUQUERQUE, 2004; BOCANEGRA e SILVA JR., 2007).

\section{CARACTERÍSTICAS GERAIS DA ÁREA DE ESTUDO}

O clima característico da Região Noroeste, baseado na classificação de Köppen, é o Aw, tropical quente e úmido com estações seca (inverno) e chuvosa (verão) bem marcadas (CEZAR, 2001). O balanço hídrico, calculado pela EMBRAPA/SOLOS (GONÇALVES et al., 2006), com dados interpolados da série histórica 1960-1990 das estações pluviométricas mais próximas de São José de Ubá (Estação Itaperuna e Santo Antônio de Pádua) também deixa claro que as chuvas são concentradas no verão, havendo um déficit hídrico nos meses de inverno, tornando a água subterrânea a única alternativa para o período de seca.

Segundo Lumbreras et al. (2006), é possível identificar na BHRSD a ocorrência de dois 
domínios pedológicos bastante distintos e intimamente relacionados às duas feições geomorfológicas regionais, ou sejam, as baixadas (várzeas) e os morros e montanhas. Na primeira foram identificados Gleissolos nas partes mais baixas e Planossolos e Cambissolos desenvolvidos de sedimentos coluvionares e colúvio-aluvionares nas posições ligeiramente mais elevadas. Consequentemente, a deficiência hídrica regional é minimizada nas baixadas. As áreas de morros e montanhas são o domínio de Argissolos Vermelhos e Vermelho-Amarelos que gradativamente dão lugar a Cambissolos e a Neossolos Litólicos à medida que o relevo fica mais acentuado, portanto regiões de maior erodibilidade e de deficiência hídrica.

Segundo Dantas (2001), do ponto de vista geomorfológico, a área de estudo situa-se em uma ampla zona colinosa, intercalada com alinhamentos serranos escalonados de direção predominante WSW-ENE, compreendendo grandes extensões do Norte/ Noroeste do Estado. A principal característica é o contraste brusco entre feições homogêneas de colinas, morrotes e morros, além de alinhamentos serranos bastante elevados.

De acordo com o mapa de favorabilidade hidrogeológica do Estado do RJ elaborado por Barreto et al. (2001), a BHRSD apresenta um potencial hidrogeológico relativamente alto. As informações utilizadas para a elaboração deste mapa são provenientes de poços situados exclusivamente no aquífero fraturado, que em geral tem caráter semiconfinado, recoberto por materiais coluviais e aluviões. Isto não exclui a importância de alguns aquíferos superficiais detríticos, principalmente pelo fato de que em algumas áreas, apesar do alto potencial, as águas contidas no aquífero fraturado podem, por exemplo, apresentar altos teores de ferro (PRADO et al., 2005) o que compromete o seu uso em muitos casos.

O município de São José de Ubá apresenta favorabilidade mediana (vazões entre 1 e $5 \mathrm{~m}^{3} / \mathrm{h}$ ) e baixa (vazões menores que $1 \mathrm{~m}^{3} / \mathrm{h}$ ) nas encostas, e alta favorabilidade (vazões maiores que $5 \mathrm{~m}^{3} / \mathrm{h}$ ) nas planícies. A média da vazão dos poços profundos cadastrados para essa pesquisa no município de São José de Ubá é de $14 \mathrm{~m}^{3} / \mathrm{h}$, considerada muito boa para cristalino. Isso se deve provavelmente à intensa deformação rúptil que esta parte do território fluminense sofreu ao longo do tempo geológico, em vários episódios deformacionais ao longo, principalmente, da chamada Faixa Paraíba do Sul.

Por meio de métodos geofísicos, como o do levantamento resistivimétrico e das inversões unidimensionais e bidimensionais, Ferreira et al. (2006), identificaram dois tipos de aquíferos em uma sub-bacia (Barro Branco - ver figura 3) da área de estudo: o sedimentar e o fissural. O aquífero sedimentar é composto por sedimentos aluviais quaternários e é caracterizado por uma camada sub-horizontal com espessura variável ao longo dos perfis (espessuras de 2 a 12 metros). O aquífero fissural é caracterizado por duas zonas sub-verticais de baixa resistividade possuindo larguras na faixa de 30 a 50 metros e profundidade superior a 30 metros.

\section{GEOLOGIA LOCAL}

De acordo com o trabalho realizado por Tupinambá et al. (2006), o curso principal do Rio São Domingos ao longo de quase toda a bacia está instalado ao longo do contato tectônico entre os terrenos ocidental e oriental, representados, respectivamente, pelos domínios tectônicos Juiz de Fora e Cambuci (figura 2). A vertente norte e as cabeceiras da bacia são ocupadas pelo Domínio tectônico Juiz de Fora, caracterizado por lentes limitadas por falhas de empurrão, cada lente contendo rochas miloníticas do Complexo Juiz de Fora ou granada biotita gnaisses (paragnaisses). A vertente sul é ocupada pelo Domínio tectônico Cambuci, onde predomina um leucocharnoquito e ocorrem, subordinadamente, anfibolitos, mármores e gnaisse migmatítico. Segundo Heilbron et al. (2005), em ambos os domínios, as rochas encontram-se cortadas por sets de fraturas, predominando os trends NNW-SSE e NE-SW (concordante com a estruturação geológica da bacia). Pode-se notar uma maior concentração de fraturas na parte norte da bacia (Domínio Juiz de Fora), provavelmente devido à heterogeneidade das rochas e uma estruturação milonítica mais pronunciada. Estas fraturas frequentemente encontram-se abertas, controlando a infiltração e a circulação da água no meio rochoso. A seguir, de acordo com a pesquisa realiza por Tupinambá et al. (2006), são descritos em maior detalhe os dois tipos litológicos que ocupam mais de $90 \%$ da área aflorante, o Complexo Juiz de Fora e o Leucocharnoquito do Domínio tectônico Cambuci.

Complexo Juiz de Fora: Toda a vertente norte, as cabeceiras e os divisores da bacia ao longo das serras do Alvarenga e Vista Alegre são constituídos por rochas granulíticas do Complexo Juiz de Fora. 
Este complexo, de idade Paleoproterozóica (2,22,0 Ga A.P.), está largamente distribuído no setor central da Faixa Ribeira, desde o vale do Rio Paraíba do Sul até a Zona da Mata Mineira. Contém rochas de grão médio a grosso, esverdeadas a escuras, com ortopiroxênio (hiperstênio), pouca biotita e hornblenda, quartzo acima de $20 \%$ e concentração variada de feldspato potássico e plagioclásio, classificadas como enderbitos e charnoquitos gnaissificados.

Leucocharnoquito: Aflora predominantemente como uma rocha leucocrática homogênea, de composição granítica a granodiorítica, com cristais isolados de biotita, piroxênio e anfibólio. Seus planos de foliação se desenvolvem com maior intensidade nas proximidades de zonas de cisalhamento, e são constituídos por lâminas submilimétricas de biotita e opacos, fitas de quartzo de comprimento centimétrico e por domínios quartzo-feldspáticos. Contém enclaves de rochas máficas, hornblenda gnaisses bandados, granada gnaisses e rochas calcissilicáticas. Do ponto de vista composicional, pode ser caracterizada como uma rocha quartzo-feldspática homogênea, salvo quando ocorre grande número de enclaves.

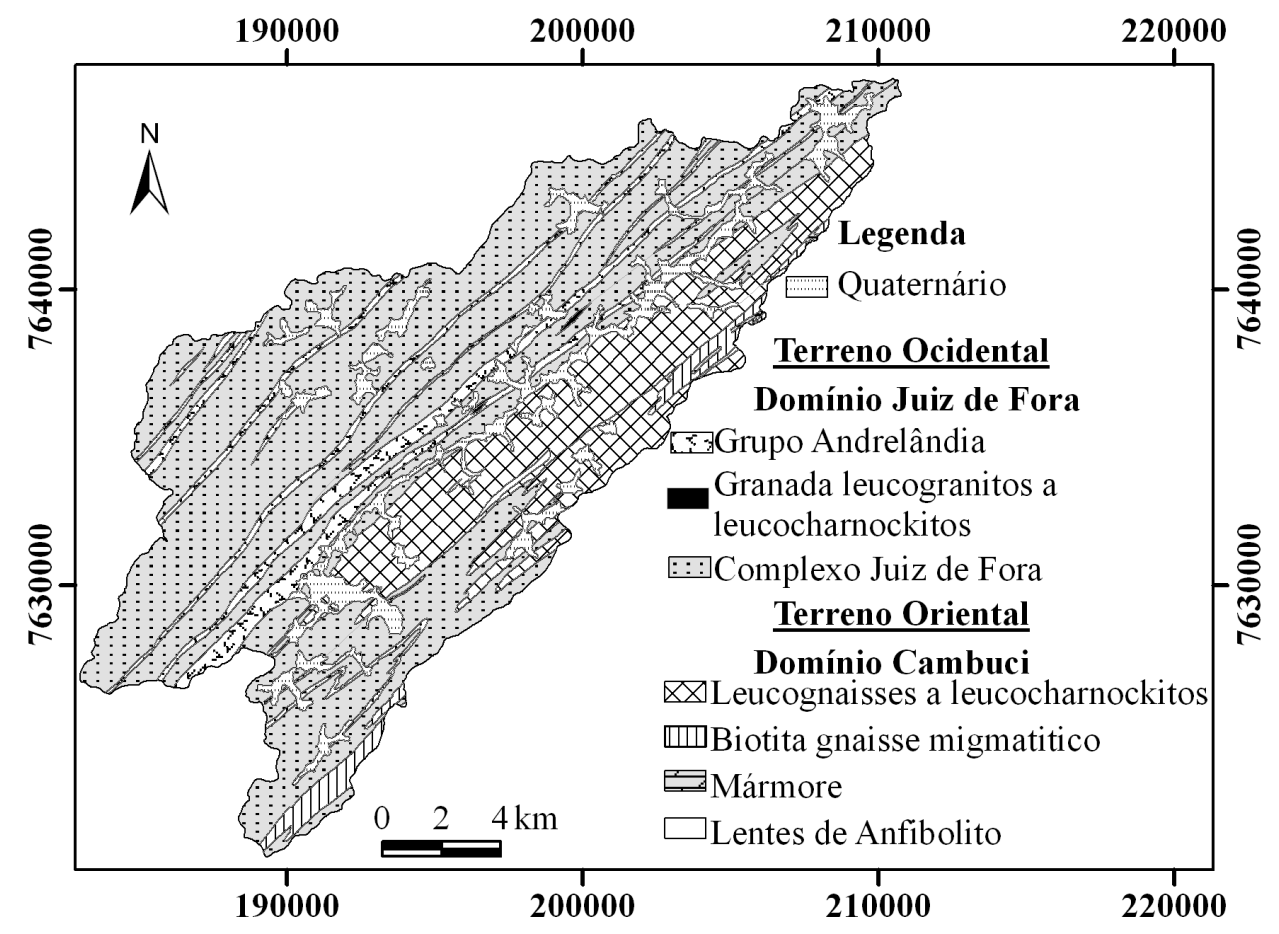

Figura 2: Mapa de Unidades Geológicas da Bacia Hidrográfica do Rio São Domingos (Tupinambá et al., 2006). Gr-granada; Bt-biotita.

\section{MÉTODOS EMPREGADOS NA ÁREA DE ESTUDO}

A partir da sobreposição dos mapas de classes de declividade, geologia, hidrografia e vias de acesso no software ArcGis ${ }^{\circledR}$ (versão 8.3 da ESRI), determinou-selocais onde os pontos de amostragem deveriam ser alocados, de forma que toda a área da bacia fosse contemplada, assim como todas as unidades geológicas. Dessa forma, foram locados e georreferenciados 65 pontos de amostragem bem distribuídos ao longo da BHRSD, sendo 28 poços rasos, 8 nascentes, 10 poços profundos e 19 pontos superficiais (figura 3). A coleta, em outubro de 2004, permitiu a obtenção in situ de valores de temperatura, $\mathrm{pH}$, condutividade elétrica (CE) e alcalinidade total (método volumétrico com ampolas Titrets ${ }^{\circledR}$ da Chemetrics). No laboratório da Embrapa Solos foram analisados a alcalinidade total e o bicarbonato pelo método titulométrico e os cátions foram determinados pela técnica de análise elementar por espectroscopia de emissão por plasma - ICP. Para determinação dos ânions utilizou-se um cromatógrafo de íons Dionex DX120 e as análises de materiais sólidos na água foram realizadas no Laboratório de Hidrogeologia da Universidade Federal do Rio de Janeiro, pelo método gravimétrico, segundo APHA (1998). Todos os dados foram inseridos em Banco de Dados Georreferenciado do $\mathrm{ArcGis}^{\circledR}$, versão 8.3 (MENEZES, 2005). 


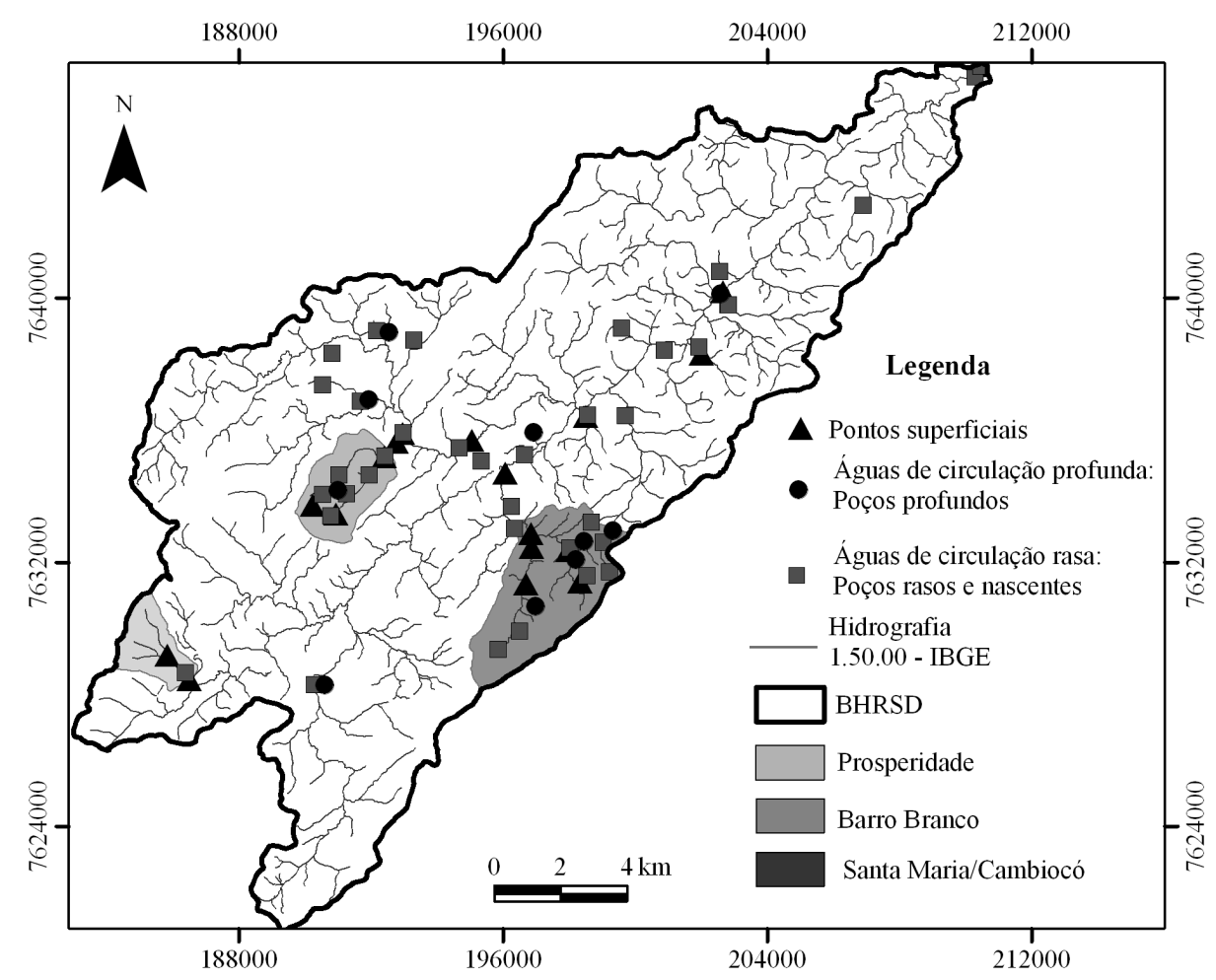

Figura 3: Pontos de amostragens de água, classificados pelo tipo de corpo de água, a saber: pontos superficiais; águas de circulação rasa: nascentes e poços rasos e águas de circulação profunda: poços profundos. Destaque para localidades importantes, cabeceira da margem ocidental: Prosperidade; próximo ao eixo da bacia: Barro Branco; e na parte oriental: Santa Maria/ Cambiocó.

\section{TRATAMENTO E INTERPRETAÇÃO DOS $D A D O S$}

Para a análise dos dados hidrogeoquímicos estes foram agrupados por tipo de água: superficial (rios, córregos e açudes), nas etapas de interpretação dos resultados, trabalhou-se apenas com o valor médio dos parâmetros dessas amostras; de circulação rasa (nascentes e poços escavados) e de circulação profunda (poços profundos). A primeira etapa de tratamento de dados para sua posterior interpretação consistiu na elaboração de uma base de dados com todos os resultados gerados com os levantamentos preliminares, levantamentos de campo e análises laboratoriais.

Em seguida, os dados das análises químicas foram exportados para o software AquaChem $^{\circledR}$ versão 3.7 (Waterloo Hydrogeologic Inc.) para elaboração de gráficos e diagramas visando a caracterização hidrogeoquímica da BHRSD.

Posteriormente, para que diferenças quantitativas existentes entre as amostras fossem melhor visualizadas, utilizou-se o método estatístico hierárquico de cluster ou análise de agrupamento. Agrande vantagemé que esse método estatístico permite identificar grupos homogêneos de uma população, levando em consideração o peso ou valor das amostras (VIDAL e CHANG, 2002). O software de análises estatísticas usado foi o $S P S S^{\circledR}$ versão 12 (SPSS Inc.) e a técnica para a medida de similaridade, que visa avaliar o grau de semelhança entre as amostras de água, foi a do quadrado da distância euclidiana. O agrupamento resultante é representado, mais adiante, através de um dendograma.

$\mathrm{Na}$ fase seguinte, criou-se uma base de dados geográficos com as informações do cadastro dos pontos d'água e das análises físico-químicas no $A r c G i s^{\circledR}$, versão 8.3. Foram realizadas interpolações com os resultados de CE, utilizando a extensão Spatial Analyst e aplicando o método de interpolação Inverse Distance Weighted (IDW), cujo peso é função da distância inversa entre os pontos amostrados. As representações gráficas elaboradas e interpretações consequentes, deram origem às discussões e conclusões apresentadas ao fim do trabalho.

\section{RESULTADOS E DISCUSSÕES}

Os resultados incluem duas partes: (1) delineamento das principais características das águas da BHRSD, classificadas quanto aos íons dissolvidos e demais componentes analisados; e (2) verificação de tendências de comportamento de acordo com análises estatísticas (cluster), cotejadas com seus aspectos geológico-estruturais, visando a determinação de possíveis tendências na associação hidrogeoquímica/ litotipos. 


\section{COMPORTAMENTO HIDROQUÍMICO DAS ÁGUAS SUBTERRÂNEAS DA BHRSD}

Estimou-se o erro de balanço iônico nas análises químicas. A média do erro obtido foi de $-2,96 \%$ e o desvio padrão de $0,16 \%$, resultado bastante adequado. A partir dos resultados das análises hidroquímicas, sumarizados na tabela 1 , verificouse que, de maneira geral, as águas da BHRSD apresentaram características bicarbonatadasmistas com tendência a bicarbonatadas-sódicas. Ocorreram, ainda, águas cloretadas-sódicas, bicarbonatadas-cálcicas e mescla dos tipos dominantes.

A comparação dos ânions indicou que as águas se comportam de maneira homogênea, e constatouse a predominância do íon bicarbonato $\left(\mathrm{HCO}_{3}^{-}\right)$ sobre o íon cloreto $\left(\mathrm{Cl}^{-}\right)$e desses sobre o íon sulfato $\left(\mathrm{SO}_{4}^{-2}\right)$. Esta característica é considerada muito comum para ambientes cristalinos, já que o conteúdo de $\mathrm{Cl}^{-}$e $\mathrm{SO}_{4}^{-2}$ nas rochas ígneas é, em geral, muito baixo (APPELO e POSTMA, 2005). Já no caso dos cátions, observou-se que o íon sódio $\left(\mathrm{Na}^{+}\right)$predominou, sendo que os demais cátions apresentaram uma variação menos regular, ora predominando o magnésio $\left(\mathrm{Mg}^{+2}\right)$, ora o cálcio $\left(\mathrm{Ca}^{+2}\right)$, mas nunca o potássio $\left(\mathrm{K}^{+}\right)$. Portanto, $\mathrm{o} \mathrm{Na}^{+}$foi quase sempre o cátion mais abundante, principalmente nas águas mais rasas, porque é liberado pelos plagioclásios, minerais presentes na área. Em geral, é isso que acontece em águas que percolam rochas cristalinas ácidas, os íons alcalinos são normalmente predominantes. A presença de $\mathrm{Ca}^{+2}$ e $\mathrm{Mg}^{+2}$ em maior quantidade ocorre de modo bastante evidente nas amostras de água dos poços profundos, o que reflete o maior tempo de contato da água subterrânea percolante com litotipos mais básicos (anfibolitos, ígneas com caráter intermediário) como observado no diagrama de Piper da figura 4.

O diagrama de Piper (figura 4) mostrou que os tipos hidroquímicos predominantes são 0 bicarbonatado-sódico e o bicarbonatado-misto para as águas dos poços rasos e profundos. Para este último tipo de captação, as águas bicarbonatadascálcicas também são importantes. Os demais tipos hidroquímicos e suas porcentagens na BHRSD são contemplados na tabela 2 .

Observou-se que as águas mais duras são as de origem profunda, mostrando maior predominância dos íons $\mathrm{Ca}^{+2} \mathrm{e} \mathrm{Mg}^{+2}$ (tabela 3). Todos os usuários dos poços profundos entrevistados reclamaram da excessiva dureza das águas subterrâneas, já que essas são incrustantes e produzem grande consumo de sabão. Alguns poços da prefeitura de São José de Ubá contam com sistemas de abrandamento da dureza, aparentemente pouco efetivos. Esse problema, portanto, é um importante elemento na avaliação das águas subterrâneas profundas dos aquíferos cristalinos da área, já que $80 \%$ das águas analisadas em poços profundos apresentam esse tipo de problema.

Tabela 1: Ânions e cátions (meq/L), Si (mg/L) e pH e CE $(\mu \mathrm{S} / \mathrm{cm})$ medidos in situ na BHRSD.

\begin{tabular}{|l|l|l|l|l|l|l|l|l|l|l|l|}
\hline ID & $\begin{array}{l}\mathrm{pH} \text { in } \\
\text { situ }\end{array}$ & $\mathrm{CE}$ & $\mathrm{Na}$ & $\mathrm{Ca}$ & $\mathrm{Mg}$ & $\mathrm{K}$ & $\mathrm{NO} 3$ & $\mathrm{HCO} 3$ & $\mathrm{Cl}$ & $\mathrm{SO} 4$ & $\mathrm{SiO} 2$ \\
\hline $1 \mathrm{~N}$ & 6,09 & 100,00 & 0,505 & 0,225 & 0,362 & 0,012 & 0,06 & 0,872 & 0,106 & 0,11 & 18,5 \\
\hline $2 \mathrm{~N}$ & 6,56 & 170,00 & 0,483 & 0,487 & 0,589 & 0,042 & 0,04 & 3,399 & 0,303 & 0,142 & 18 \\
\hline $7 \mathrm{~N}$ & 6,73 & 160,00 & 0,744 & 0,414 & 0,831 & 0,015 & 0,05 & 1,712 & 0,165 & 0,093 & 17,5 \\
\hline $25 \mathrm{~N}$ & 6,6 & 120,00 & 0,735 & 0,137 & 0,228 & 0,011 & 0,02 & 0,748 & 0,214 & 0,246 & 8,11 \\
\hline $33 \mathrm{~N}$ & 5,96 & 100,00 & 0,424 & 0,112 & 0,142 & 0,012 & 0,10 & 0,6 & 0,081 & 0,068 & 18,6 \\
\hline $34 \mathrm{~N}$ & 5,34 & 110,00 & 0,425 & 0,071 & 0,109 & 0,029 & 0,16 & 0,176 & 0,334 & 0,014 & 16,7 \\
\hline $35 \mathrm{R}$ & 6,12 & 140,00 & 0,87 & 0,206 & 0,238 & 0,005 & 0,02 & 1,040 & 0,183 & 0,252 & 16,1 \\
\hline $38 \mathrm{~N}$ & 6,86 & 300,00 & 1,440 & 0,438 & 0,88 & 0,017 & 0,08 & 1,836 & 0,109 & 0,801 & 22,5 \\
\hline $43 \mathrm{~N}$ & 6,82 & 160,00 & 1,344 & 0,182 & 0,192 & 0,003 & 0,07 & 1,400 & 0,186 & 0,105 & 33,5 \\
\hline $52 \mathrm{~N}$ & 6,05 & 170,00 & 0,84 & 0,224 & 0,244 & 0,095 & 0,08 & 0,8 & 0,476 & 0,105 & 18,6 \\
\hline $8 \mathrm{R}$ & 6,59 & 300,00 & 1,997 & 0,351 & 0,77 & 0,01 & 0,04 & 0 & 0,404 & 0,278 & 17,3 \\
\hline $11 \mathrm{R}$ & 6,13 & 200,00 & 0,822 & 0,519 & 0,709 & 0,017 & 0,01 & 1,760 & 0,225 & 0,268 & 11,6 \\
\hline $12 \mathrm{R}$ & 6,69 & 430,00 & 1,657 & 0,274 & 0,391 & 0,026 & 0,10 & 3,763 & 0,367 & 0,25 & 23,3 \\
\hline $13 \mathrm{R}$ & 5,98 & 220,00 & 1,218 & 0,483 & 0,348 & 0,009 & 0,24 & 1,092 & 0,71 & 0,155 & 22,0 \\
\hline $14 \mathrm{R}$ & 6,41 & 210,00 & 3,380 & 0,749 & 1,012 & 0,023 & 0,15 & 1,600 & 0,568 & 0,383 & 21,9 \\
\hline $15 \mathrm{R}$ & 6,39 & 350,00 & 1,140 & 0,908 & 1,415 & 0,016 & 0,04 & 2,451 & 0,51 & 0,386 & 20,9 \\
\hline $16 \mathrm{R}$ & 6,3 & 470,00 & 2,210 & 0,554 & 1,160 & 0,21 & 0,21 & 1,668 & 1,489 & 0,955 & 19,5 \\
\hline
\end{tabular}




\begin{tabular}{|c|c|c|c|c|c|c|c|c|c|c|c|}
\hline $18 \mathrm{R}$ & 6,64 & 320,00 & 1,866 & 0,402 & 0,68 & 0,01 & 0,06 & 1,948 & 0,616 & 0,231 & 26,3 \\
\hline $19 \mathrm{R}$ & 5,62 & 310,00 & 1,744 & 0,484 & 0,781 & 0,008 & 0,12 & 2,399 & 0,564 & 0,258 & 27,2 \\
\hline $20 \mathrm{R}$ & 6,82 & 770,00 & 2,519 & 1,856 & 1,842 & 0,05 & 0,08 & 0,588 & 5,683 & 0,056 & 18,4 \\
\hline $21 R$ & 7,3 & 200,00 & 0,395 & 0,788 & 0,656 & 0,054 & 0,06 & 1,636 & 0,3 & 0,023 & 24,3 \\
\hline $23 \mathrm{R}$ & 6,28 & 1010,00 & 2,601 & 3,164 & 2,188 & 1,146 & 0,20 & 6,179 & 2,272 & 0,458 & 13,8 \\
\hline $24 \mathrm{R}$ & 6,39 & 660,00 & 3,254 & 1,876 & 1,480 & 0,062 & 0,29 & 2,803 & 1,537 & 2,277 & 15,1 \\
\hline $25 \mathrm{R}$ & 5,77 & 90,00 & 0,336 & 0,151 & 0,111 & 0,016 & 0,02 & 0,492 & 0,12 & 0,053 & 10,9 \\
\hline $26 \mathrm{R}$ & 6,06 & 280,00 & 0,935 & 0,501 & 0,938 & 0,014 & 0,26 & 1,256 & 0,958 & 0,06 & 24,6 \\
\hline $27 \mathrm{R}$ & 6,62 & 330,00 & 1,018 & 1,507 & 0,756 & 0,115 & 0,32 & 2,531 & 0,582 & 0,29 & 14,8 \\
\hline $28 \mathrm{R}$ & 6,06 & 110,00 & 0,744 & 0,118 & 0,067 & 0,018 & 0,05 & 0,74 & 0,198 & 0,037 & 26,6 \\
\hline $29 \mathrm{R}$ & 6,46 & 170,00 & 0,879 & 0,501 & 0,227 & 0,029 & 0,10 & 1,376 & 0,305 & 0,069 & 24,6 \\
\hline $31 \mathrm{R}$ & 5,22 & 120,00 & 0,535 & 0,045 & 0,151 & 0,035 & 0,03 & 0,228 & 0,631 & 0,052 & 8,46 \\
\hline $36 \mathrm{R}$ & 6,31 & 420,00 & 2,097 & 0,933 & 1,209 & 0,022 & 0,25 & 2,751 & 1,719 & 0,217 & 18,8 \\
\hline $39 \mathrm{R}$ & 6,42 & 230,00 & 1,131 & 0,304 & 0,713 & 0,018 & 0,11 & 1,628 & 0,147 & 0,304 & 25,4 \\
\hline $41 \mathrm{R}$ & 5,92 & 100,00 & 0,503 & 0,154 & 0,112 & 0,012 & 0,04 & 1,200 & 0,134 & 0,039 & 25,9 \\
\hline $43 R$ & 6,75 & 820,00 & 3,854 & 2,280 & 2,023 & 0,035 & 0,08 & 5,427 & 3,785 & 2,785 & 20,6 \\
\hline $44 \mathrm{R}$ & 6,91 & 880,00 & 3,732 & 2,315 & 2,796 & 0,041 & 0,08 & 6,575 & 1,808 & 1,349 & 22,3 \\
\hline $48 \mathrm{R}$ & 5,95 & 140,00 & 0,957 & 0,145 & 0,18 & 0,008 & 0,07 & 1,124 & 0,157 & 0,082 & 25,4 \\
\hline $52 \mathrm{R}$ & 6,06 & 280,00 & 1,509 & 0,297 & 0,427 & 0,012 & 0,14 & 0,856 & 1,257 & 0,216 & 21,1 \\
\hline $53 \mathrm{R}$ & 5,94 & 260,00 & 0,97 & 0,803 & 0,438 & 0,038 & 0,29 & 1,152 & 0,834 & 0,133 & 20,4 \\
\hline $2 \mathrm{P}$ & 6,62 & 260,00 & 0,835 & 0,694 & 0,888 & 0,035 & 0,00 & 1,776 & 0,587 & 0,135 & 15,9 \\
\hline $4 \mathrm{P}$ & 7,16 & 810,00 & 3,115 & 4,800 & 1,587 & 0,074 & 0,03 & 6,315 & 1,143 & 2,925 & 20,6 \\
\hline $7 \mathrm{P}$ & 7,35 & 440,00 & 2,488 & 2,011 & 1,012 & 0,048 & 0,06 & 3,827 & 0,852 & 0,528 & 22,0 \\
\hline $8 \mathrm{P}$ & 6,88 & 350,00 & 2,523 & 0,763 & 0,822 & 0,029 & 0,02 & 2,559 & 0,73 & 0,775 & 0,00 \\
\hline $12 \mathrm{P}$ & 6,99 & 1640,00 & 2,014 & 10,978 & 5,683 & 0,128 & 0,02 & 10,808 & 0,66 & 7,380 & 0,00 \\
\hline $17 \mathrm{P}$ & 6,31 & 300,00 & 0,557 & 1,742 & 0,995 & 0,056 & 0,00 & 2,799 & 0,508 & 0,258 & 0,00 \\
\hline 19P & 6,6 & 650,00 & 1,849 & 2,360 & 2,360 & 0,069 & 0,00 & 3,399 & 0,737 & 2,460 & 0,00 \\
\hline $20 \mathrm{P}$ & 6,51 & 440,00 & 1,531 & 1,632 & 1,266 & 0,049 & 0,03 & 3,467 & 0,541 & 0,462 & 0,00 \\
\hline $21 \mathrm{P}$ & 6,43 & 630,00 & 3,202 & 1,886 & 1,595 & 0,054 & 0,13 & 3,599 & 1,498 & 1,650 & 0,00 \\
\hline $60 \mathrm{P}$ & 6,31 & 350,00 & 2,171 & 0,456 & 0,594 & 0,035 & 0,04 & 1,564 & 1,168 & 0,374 & 0,00 \\
\hline $1 \mathrm{~S}$ & 7,24 & 160,00 & 0,474 & 0,424 & 0,487 & 0,049 & 0,00 & 1,264 & 0,19 & 0,019 & 0,00 \\
\hline $6 \mathrm{~S}$ & 7,62 & 320,00 & 1,440 & 0,749 & 0,929 & 0,156 & 0,00 & 2,224 & 0,987 & 0,029 & 10,2 \\
\hline $7 \mathrm{~S}$ & 7,69 & 300,00 & 1,427 & 0,803 & 0,905 & 0,139 & 0,00 & 2,703 & 0,577 & 0,012 & 11,2 \\
\hline $9 \mathrm{~S}$ & 7,64 & 260,00 & 0,996 & 0,554 & 0,786 & 0,373 & 0,00 & 2,599 & 0,574 & 0,034 & 5,73 \\
\hline $12 \mathrm{~S}$ & 7,00 & 270,00 & 1,105 & 0,539 & 0,675 & 0,188 & 0,01 & 1,400 & 0,899 & 0,123 & 8,98 \\
\hline $17 \mathrm{~S}$ & 6,97 & 200,00 & 0,744 & 0,449 & 0,519 & 0,149 & 0,05 & 1,200 & 0,562 & 0,059 & 8,41 \\
\hline $19 \mathrm{~S}$ & 6,83 & 170,00 & 0,657 & 0,421 & 0,491 & 0,149 & 0,01 & 1,212 & 0,486 & 0,069 & 7,78 \\
\hline $20 \mathrm{~S}$ & 5,63 & 120,00 & 0,427 & 0,21 & 0,314 & 0,031 & 0,07 & 0,8 & 0,138 & 0,134 & 16,3 \\
\hline $21 \mathrm{~S}$ & 6,89 & 270,00 & 0,77 & 0,803 & 0,979 & 0,06 & 0,00 & 2,399 & 0,177 & 0,032 & 20,0 \\
\hline $22 \mathrm{~S}$ & 6,85 & 200,00 & 0,661 & 0,472 & 0,557 & 0,112 & 0,00 & 1,324 & 0,425 & 0,022 & 8,14 \\
\hline $23 \mathrm{~S}$ & 6,85 & 170,00 & 0,679 & 0,398 & 0,447 & 0,172 & 0,02 & 1,200 & 0,53 & 0,083 & 8,66 \\
\hline $24 \mathrm{~S}$ & 7,02 & 240,00 & 1,231 & 0,604 & 0,752 & 0,147 & 0,00 & 2,152 & 0,431 & 0,011 & 8,43 \\
\hline $27 \mathrm{~S}$ & 7,75 & 330,00 & 1,383 & 0,664 & 0,872 & 0,214 & 0,00 & 2,399 & 0,778 & 0,101 & 4,8 \\
\hline $29 \mathrm{~S}$ & 7,71 & 390,00 & 2,384 & 1,048 & 1,135 & 0,178 & 0,00 & 3,639 & 0,813 & 0,283 & 9,45 \\
\hline $30 \mathrm{~S}$ & 7,01 & 330,00 & 1,479 & 0,933 & 1,069 & 0,142 & 0,00 & 2,927 & 0,618 & 0,023 & 8,25 \\
\hline $32 \mathrm{~S}$ & 8,24 & 220,00 & 1,266 & 0,361 & 0,673 & 0,103 & 0,00 & 1,844 & 0,524 & 0,046 & 5,68 \\
\hline $36 \mathrm{~S}$ & 7,43 & 140,00 & 0,374 & 0,405 & 0,446 & 0,034 & 0,00 & 1,200 & 0,13 & 0,03 & 9,42 \\
\hline $37 \mathrm{~S}$ & 7,04 & 160,00 & 0,635 & 0,328 & 0,391 & 0,202 & 0,01 & 0,924 & 0,473 & 0,122 & 8,4 \\
\hline
\end{tabular}

$\mathbf{N}=$ Nascentes, $\mathbf{R}=$ Poços rasos, $\mathbf{P}=$ Poços profundos, $\mathbf{S}=$ Pontos superficiais. 


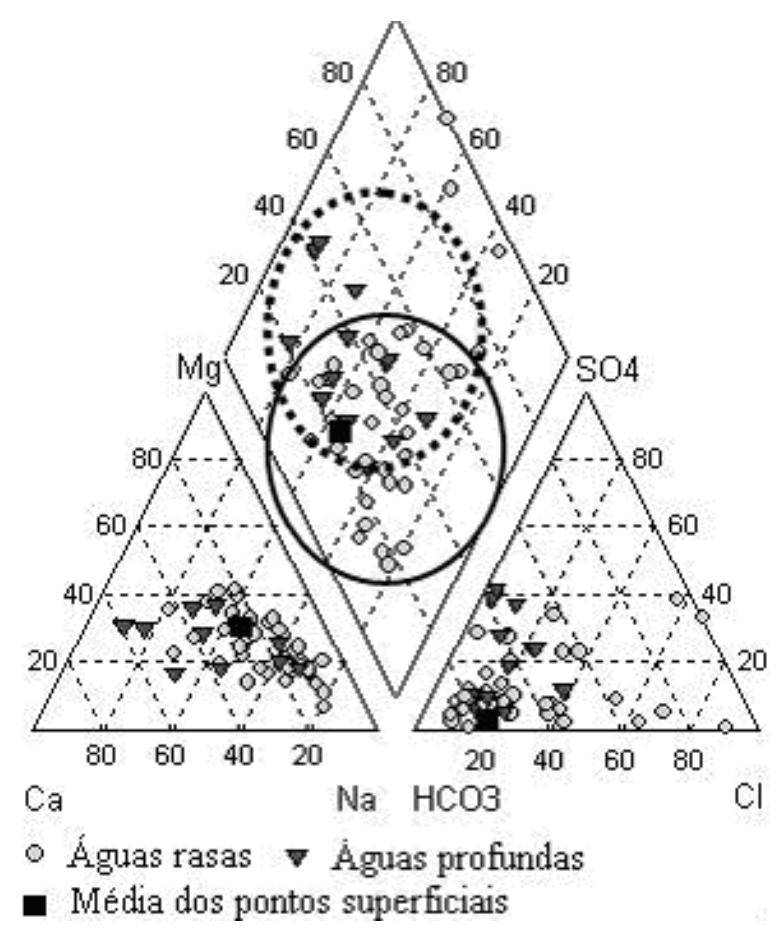

Figura 4: Diagrama de Piper ilustrando as composições químicas das águas subterrâneas de circulação rasa (poços escavados e nascentes), de circulação profunda (poços profundos) e da média dos pontos superficiais da BHRSD. O círculo de linha sólida mostra a concentração da maior parte das águas de circulação rasa e o círculo pontilhado aponta a concentração das águas de circulação profunda.

Tabela 2: Classificação das águas da BHRSD segundo o tipo hidroquímico predominante.

\begin{tabular}{|c|c|c|}
\hline $\begin{array}{c}\text { Tipo } \\
\text { hidroquímico }\end{array}$ & Águas rasas & $\begin{array}{c}\text { Águas } \\
\text { profundas }\end{array}$ \\
\hline $\mathrm{HCO}_{3}$-Na & $45,96 \%$ & $20,00 \%$ \\
\hline $\mathrm{HCO}_{3}$-mista & $32,43 \%$ & $50,00 \%$ \\
\hline $\mathrm{HCO}_{3}$-Ca & --- & $30,00 \%$ \\
\hline $\mathrm{Cl}-\mathrm{Na}$ & $10,81 \%$ & --- \\
\hline Mista-mista & $5,40 \%$ & --- \\
\hline Mista-Na & $2,70 \%$ & --- \\
\hline Cl-mista & $2,70 \%$ & --- \\
\hline
\end{tabular}

Tabela 3: Classificação das águas da BHRSD segundo a dureza em mg/L de $\mathrm{CaCO}^{3}$.

\begin{tabular}{|c|c|c|c|c|}
\hline $\begin{array}{c}\text { Tipos de } \\
\text { Dureza }\end{array}$ & $\begin{array}{c}\text { Teor de } \mathrm{CaCO}_{\mathbf{3}} \\
(\mathbf{m g} / \mathbf{L})\end{array}$ & $\begin{array}{c}\text { Águas rasas } \\
(\mathbf{\%})\end{array}$ & $\begin{array}{c}\text { Águas profundas } \\
(\mathbf{\%})\end{array}$ & $\begin{array}{c}\text { Pontos superficiais } \\
(\%)\end{array}$ \\
\hline Branda & $0-50$ & 47 & 0 & 35 \\
\hline Pouco Dura & $50-100$ & 30,5 & 20 & 53 \\
\hline Dura & $100-200$ & 14 & 40 & 12 \\
\hline Muito Dura & $>200$ & 8,5 & 40 & 0 \\
\hline
\end{tabular}


Calculou-se o índice de troca de bases (itb) e na maioria das amostras os índices calculados resultaram em valores negativos. Esses resultados indicam uma deficiência de íons de $\mathrm{Ca}^{+2}$, que provém, em geral, da troca do $\mathrm{Ca}^{+2}$ por $\mathrm{Na}^{+}$ na solução. Por isso a predominância do tipo hidroquímico bicarbonatado-sódico sobre o bicarbonatado-cálcico.

Os resultados negativos também sugerem uma água que inicialmente teve uma composição iônica equilibrada, do tipo alcalino-terroso $\left(\mathrm{Ca}^{+2}+\mathrm{Mg}^{+2}=\mathrm{SO}_{4}^{-2}+\mathrm{NO}_{3}^{-}\right)$e que sofreu uma troca com íons alcalinos do aquífero. Poderiam indicar também, a ocorrência de um processo de salinização do solo. Contudo, tais resultados podem estar relacionados ao fato de a água estar circulando em rochas cristalinas que, quase sempre, possuem os índices negativos pela simples dissolução das rochas, que liberam mais íons alcalinos do que íons de cloreto (FENZL, 1988).

Em algumas amostras os índices foram bastante positivos, indicando a ocorrência de um processo de endurecimento da água. Essas amostras estão concentradas na localidade de Barro Branco, onde os habitantes reclamam bastante da dureza da água, e em Santa Maria/Cambiocó. Tais localidades encontram-se em unidades litológicas distintas e por isso especula-se que fraturas profundas interconectadas, por exemplo, poderiam estar afetando tais resultados.

\section{CLASSIFICAÇÃO DA ÁGUA E ANÁLISE DE AGRUPAMENTO}

As variáveis utilizadas para a análise de cluster, apresentadas no dendograma da figura 5 , foram as concentrações de sódio, potássio, cálcio, magnésio, sílica, bicarbonato, cloreto e sulfato. As amostras foram separadas por símbolos de acordo com a divisão de grupos indicada pelo dendograma e plotadas no diagrama de Piper (figura 6).

Como citado anteriormente, as famílias hidroquímicas que concentram a maior parte das amostras são a bicarbonatada-sódica e bicarbonatada-mista para as águas dos poços rasos e profundos e somente para este último as classificadas como bicarbonatadas-cálcicas também são relevantes. O dendograma indicou seis grupos, sendo dois grandes agrupamentos, três amostras individualizadas, e um grupo com três amostras. A amostra 12P foi a que se apresentou de forma mais diferenciada, por causa do elevado valor do coeficiente de distância euclidiana em relação às demais águas. Os tipos hidroquímicos sugeridos pelo dendograma foram correlacionados com as variáveis (parâmetros) do banco de dados e, dentre todas, a variável condutividade elétrica (CE) mostrou maior relação com a divisão dos grupos. Através do histograma de CE (figura 7), a visualização dessa relação pode ser feita e constata-se, que de forma geral, ocorre um aumento da concentração da $\mathrm{CE}$ entre as águas do tipo I e do tipo VI. Houve uma pequena sobreposição dos tipos hidroquímicos, mas é possível notar distinção entre os grupos. Essa boa distribuição entre os agrupamentos também pôde ser observada com outras variáveis, entretanto, depois da CE foi o bicarbonato que obteve comportamento mais marcante.

O grupo I apresentou salinidade entre 90 a $470 \mu \mathrm{S} / \mathrm{cm}$ e concentrou $61 \%$ das amostras. A maior parte das águas foi classificada como bicarbonatada-sódica, mas também foram encontradas as bicarbonatadas-mistas e cloretadassódicas nesse grupo. Com o aumento da salinidade houve um aumento do sódio, potássio e do magnésio.

A salinidade do grupo II variou de 210 a 810 $\mu \mathrm{S} / \mathrm{cm}$. Esse grupo reuniu $23 \%$ das amostras, que apresentaram composição bicarbonatada-mista, bicarbonatada-sódica, bicarbonatada-cálcica e mescladas. Com o aumento da salinidade houve um aumento do potássio e sulfato.

O grupo III (cloretada-mista, $770 \mu \mathrm{S} / \mathrm{cm}$ ), assim como o grupo IV (bicarbonatada-sódica, $350 \mu \mathrm{S} / \mathrm{cm}$ ) e grupo VI (bicarbonatada-cálcica, $1640 \mu \mathrm{S} / \mathrm{cm}$ ), são compostos por uma amostra. A amostra do grupo IV apresenta valor de Si dez vezes maior que a média do restante das amostras. Um fato que poderia justificar esse alto valor é a ocorrência de algum erro analítico. 


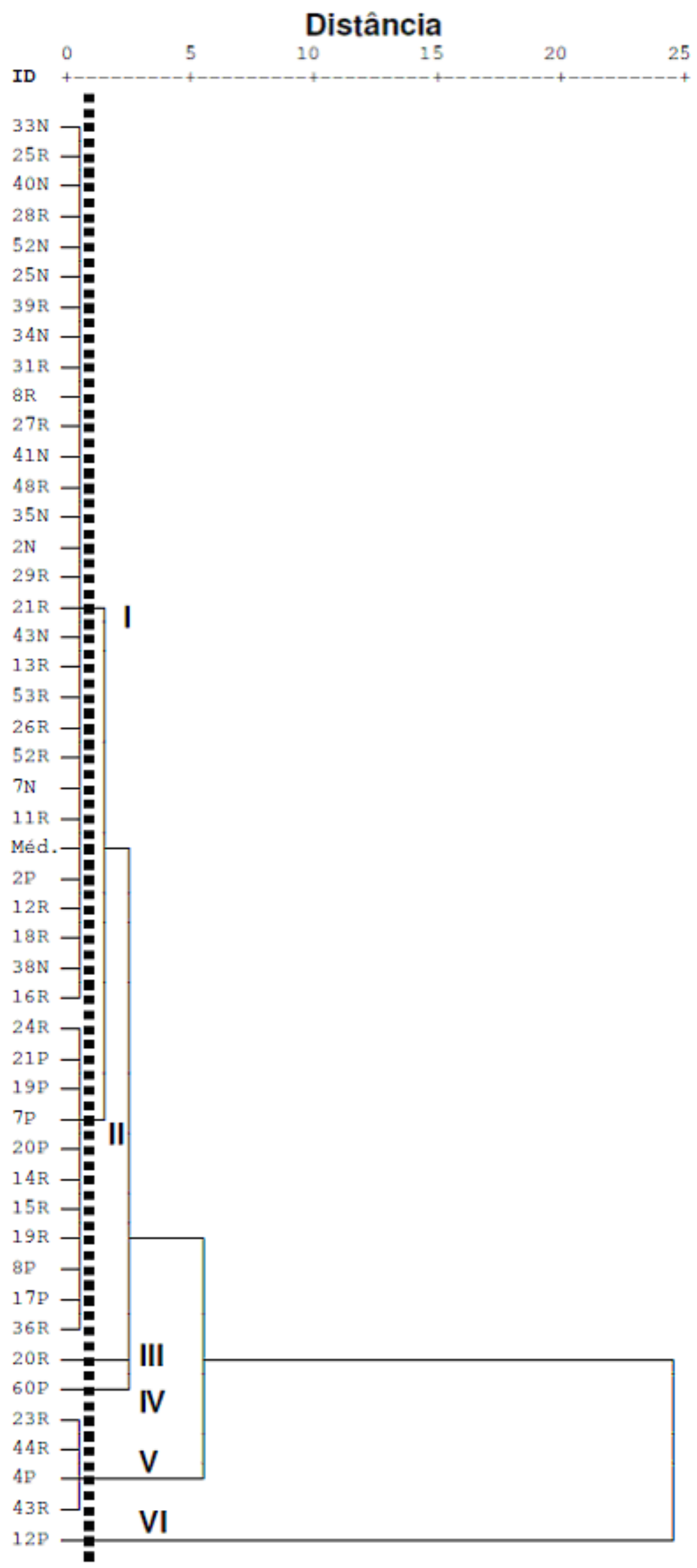

Figura 5: Dendograma mostrando os seis grupos sugeridos e a linha pontilhada representa o corte no dendograma. Méd.: média dos pontos superficiais. 


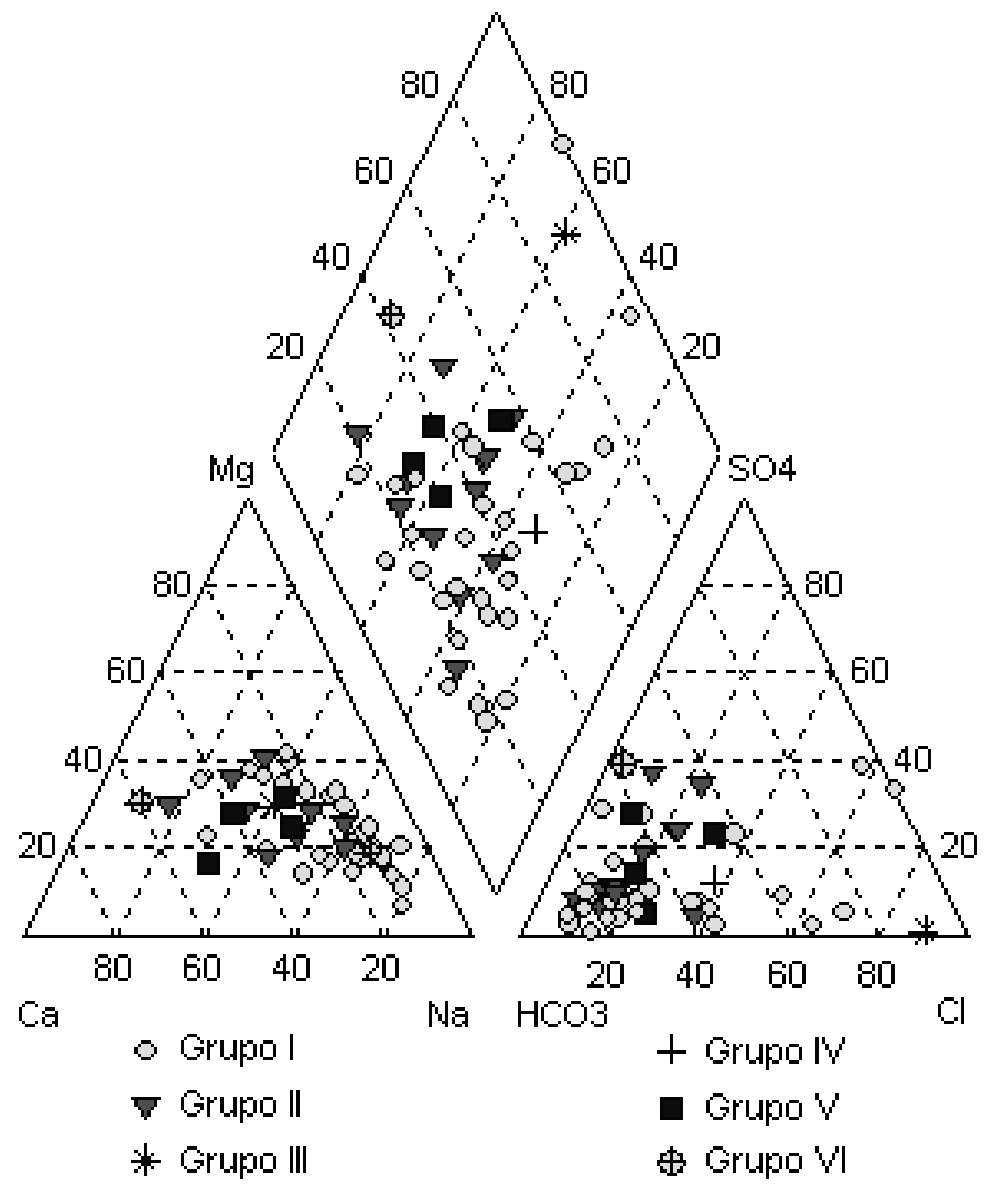

Figura 6: Diagrama de Piper para as amostras provenientes da BHRSD com icones diferentes para cada um dos seis grupos sugeridos pela análise de cluster.

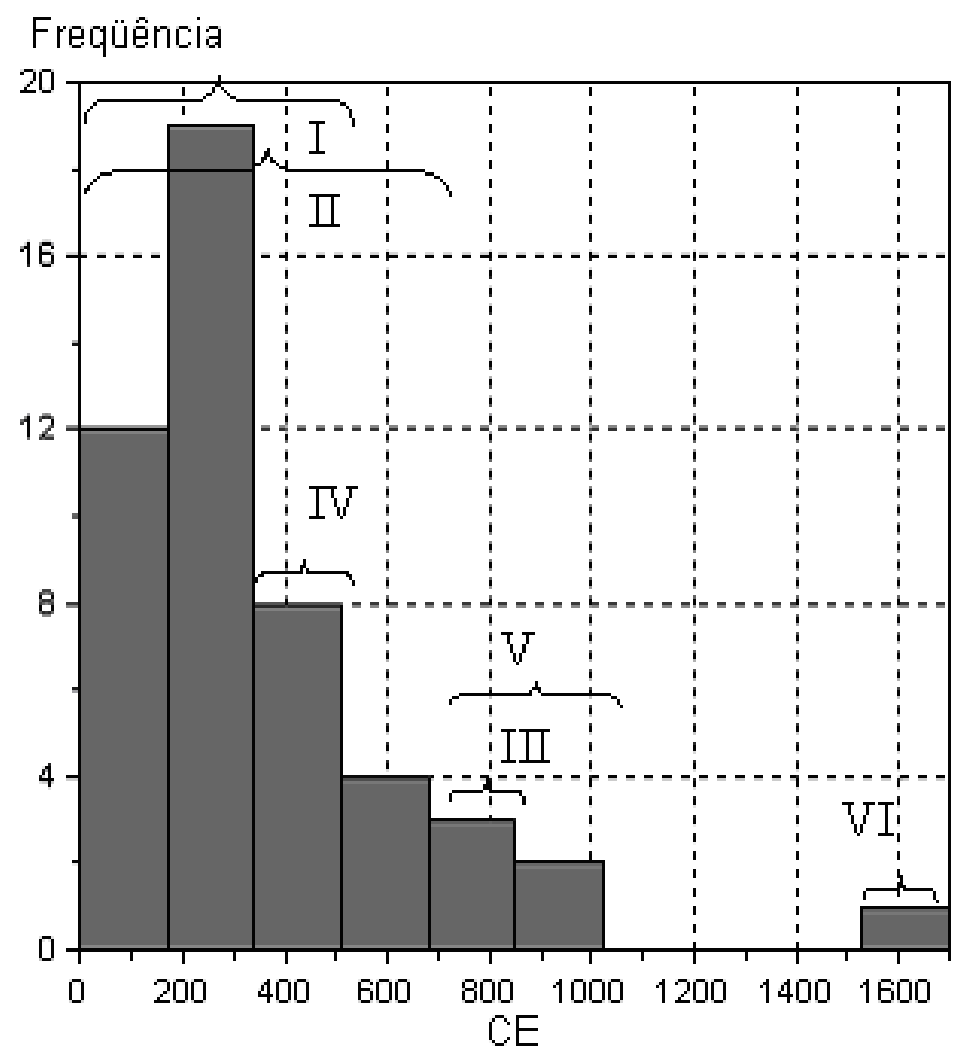

Figura 7: Histograma de condutividade elétrica $(\mu \mathrm{S} / \mathrm{cm})$ referente aos seis tipos hidroquímicos. 
A amostra individualizada no grupo III (poço raso 20R) está localizado a jusante do lançamento dos resíduos retirados da operação de redução de dureza realizada nas águas oriundas do poço profundo 12P (grupo VI). Portanto, o poço 20R recebe todo o sal retirado das águas do $12 \mathrm{P}$ e por conseguinte deve estar sendo contaminado.

Mesmo que o corte no dendograma, figura 5, tivesse sido mais acima, a amostra 12P (grupo VI), por apresentar diversas variáveis com valores mais elevados, continuaria individualizada, fato esse que não ficou tão latente se analisarmos somente o diagrama de Piper. Nota-se que, tanto as amostras do grupo V como as do VI apresentaram valores muito elevados de salinidade, superando os padrões de potabilidade e uso para irrigação. Aparentemente, tal salinidade, pode ser justificada pela percolação de água subterrânea em níveis mais profundos, ocasionando um íntimo contato com os materiais geológicos presentes, levando ao incremento significativo do conteúdo salino. Essa explicação, contudo, parece insuficiente para justificar valores tão altos como o do poço
12P, levando à suspeita de alguma litologia particularmente suscetível à dissolução, como materiais carbonáticos metamórficos ou, ainda, processos de evaporação em sistema fratura-solo, comuns em ambientes mais áridos, hipótese a ser comprovada em estudos mais dirigidos.

A condutividade elétrica do agrupamento $\mathbf{V}$ varia entre 440 a $1010 \mu \mathrm{S} / \mathrm{cm}$ e são encontradas as famílias hidroquímicas bicarbonatada-mista, bicarbonatada-cálcica e mescla desses tipos. Este grupo representa um pouco mais de $8 \%$ das amostras. Com o aumento da CE há um aumento dos íons cálcio, magnésio e potássio.

As áreas mais escuras nos mapas de distribuição espacial da CE (figuras 8 e 9) correspondem aos valores mais elevados. São nessas áreas que os agrupamentos mais individualizados (III, IV, V, VI) se concentram. É possível notar ainda que, tanto no mapa das águas subterrâneas de circulação rasa quanto no de circulação profunda, as áreas que possuem águas com maior condutividade elétrica são, de forma geral, correspondentes. São áreas que merecem novas investigações.

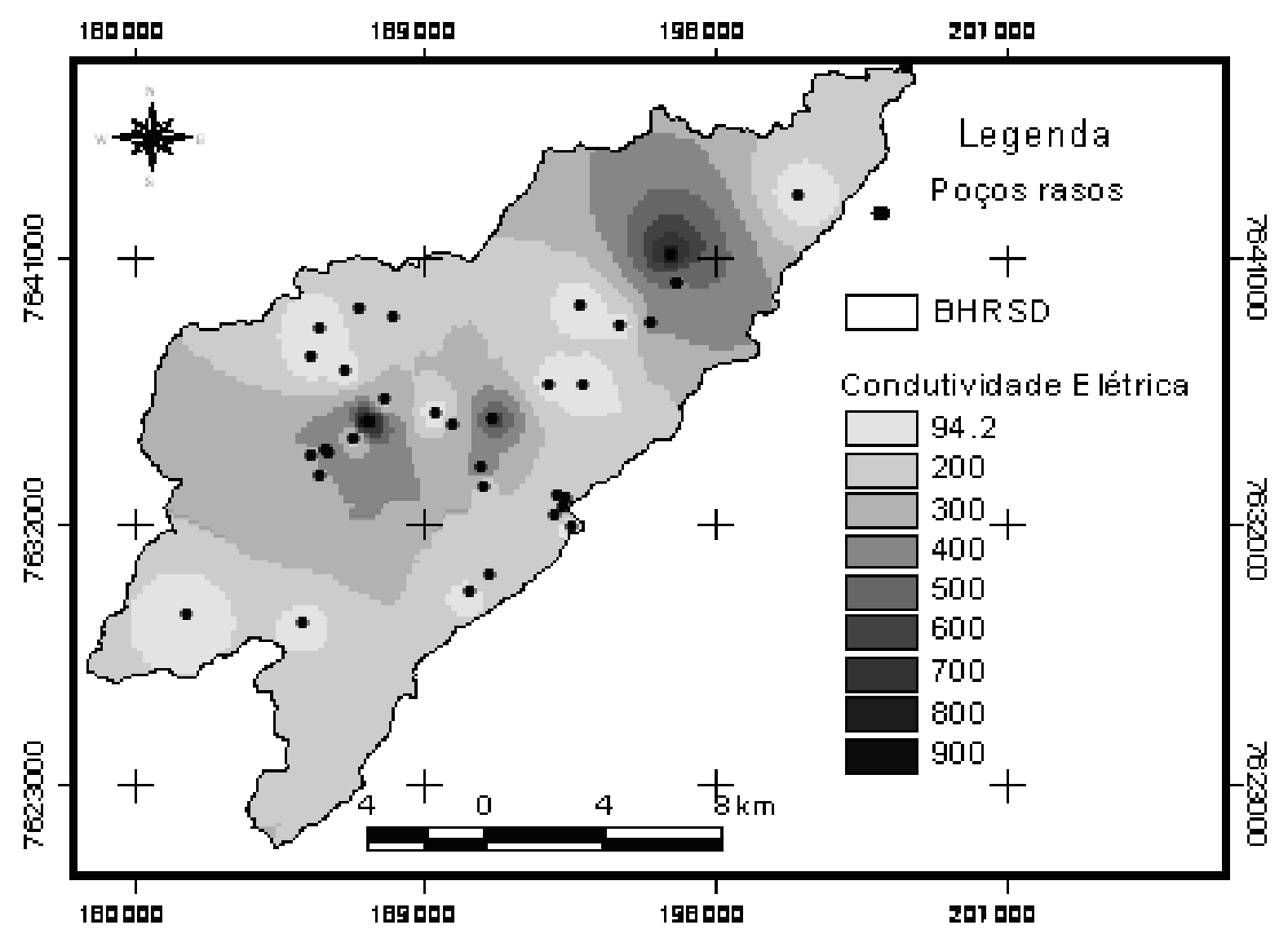

Figura 8: Mapa de distribuição espacial de CE $(\mu \mathrm{S} / \mathrm{cm})$ das águas subterrâneas de circulação rasa (poços escavados e nascentes) da Bacia Hidrográfica do Rio São Domingos. 


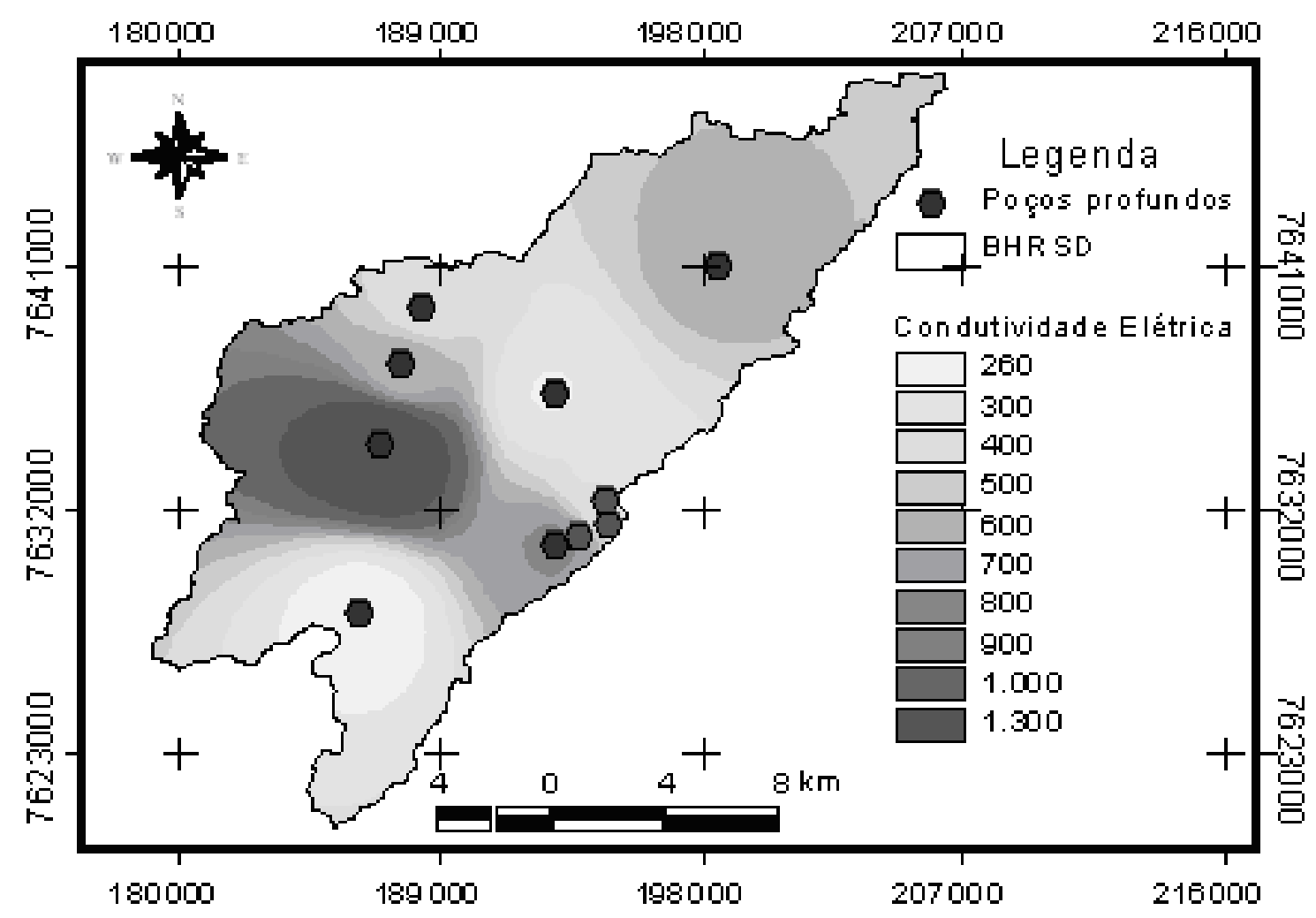

Figura 9: Mapa de distribuição espacial de $C E(\mu S / \mathrm{cm})$ das águas subterrâneas de circulação profunda (poços profundos) da Bacia Hidrográfica do Rio São Domingos.

\section{CONCLUSÕES}

A composição química das águas da Bacia Hidrográfica do Rio São Domingos foi definida, predominantemente, como bicarbonatada-mista com tendência à bicarbonatada-sódica.

As águas do aquífero raso foram as que apresentaram a maior variedade de tipos hidroquímicos, por conta da influência do tipo de solo e de processos que dependem da vegetação, clima e influência antrópica, mas a maioria das amostras desses aquíferos enquadrou-se como bicarbonatada-sódica ou bicarbonatada-mista. Sendo que, $50 \%$ das amostras correspondem a este último tipo.

Nas águas profundas, no entanto, a presença de $\mathrm{Ca}^{+2} \mathrm{e} \mathrm{Mg}^{+2}$ em maior quantidade ocorre de modo bastante evidente, o que deve refletir o maior tempo de contato da água subterrânea percolante com materiais mais básicos, anfibolitos, ígneas com caráter intermediário.

Em 28\% das amostras analisadas, nenhum par de cátion-ânion excedeu $50 \%$, refletindo um ambiente de percolação das águas subterrâneas bastante heterogêneo, com fenômenos de dissolução em sub-superfície dominados pela ação do ácido carbônico em porções rasas do perfil do subsolo.
As águas mais duras são as de origem profunda, já que, $80 \%$ das águas dos poços profundos analisadas apresentaram dureza elevada e mostraram maior predominância dos íons cálcio e magnésio. A percolação de água subterrânea em níveis mais profundos deve estar ocasionando um íntimo contato com os materiais geológicos presentes, levando ao incremento significativo do conteúdo salino. Outra hipótese é que podem estar ocorrendo processos de evaporação em sistemas fratura-solo, comuns em ambientes mais áridos, hipótese a ser comprovada em estudos mais dirigidos.

$\mathrm{Na}$ maioria das amostras os índices de troca de bases calculados foram negativos, indicando uma deficiência de íons de $\mathrm{Ca}^{+2}$, que provém em geral da troca do $\mathrm{Ca}^{+2}$ por $\mathrm{Na}^{+}$, o que justificaria o predomínio do tipo hidroquímico bicarbonatadosódico. Considera-se, porém, o fato de a água estar circulando em rochas cristalinas que, quase sempre, possuem os índices negativos pela simples dissolução das rochas, que liberam mais íons alcalinos do que de cloreto.

$\mathrm{O}$ método estatístico hierárquico de cluster ou análise de agrupamento mostrou-se eficiente para identificar as diferenças quantitativas existentes 
entre as amostras, muitas vezes, mascaradas quando as classificações ocorrem a partir de concentrações que são representadas como razões.

Observou-se, a partir da análise de cluster em conjunto com o diagrama de Piper, um aumento na heterogeneidade química das amostras com o aumento da salinização, reforçando a idéia de uma percolação em meios e materiais heterogêneos, que levaria ao enriquecimento de diferentes sais, à medida que se processa o fluxo. $\mathrm{O}$ aumento da salinidade foi, na maioria das vezes, seguido pelo aumento do teor de bicarbonato.

A análise de cluster mostrou que algumas amostras apresentaram um caráter individualizado. Representado, de forma geral, por uma maior salinidade e, principalmente, maior concentração de bicarbonato. São pontos de amostragens que devem ser objeto de novas investigações, uma vez que não foi possível sistematizar o comportamento ou associá-las de modo conclusivo à características lito-estruturais locais.

\section{REFERÊNCIAS BIBLIOGRÁFICAS}

APPELO, C.A.J.; POSTMA, D. Geochemistry, Groundwater and Pollution. Rotterdam, Holanda: Balkema, 2005. $2^{\text {a }}$ Ed. 536 p.

APHA. American Public Health Association, American Water Works Association, Water Environment Federation. Standard Methods for the Examination of Water and Wastewater. Washington: Ed. Byrd. Repress Springfield, 1998. $1.134 \mathrm{p}$.

BARRETO, A.B.C.; MONSORES, A.L.M.; LEAL, A.S.; PIMENTEL, J. Hidrogeologia do Estado do Rio de Janeiro - Texto explicativo do Mapa de Favorabilidade Hidrogeológica do Estado do Rio de Janeiro. Rio de Janeiro: CPRM, DRM/RJ, 2001. 23p.

BERTACHINI, A.C. Estudo das Características Hidrogeológicas dos Terrenos Cristalinos sob Clima Úmido, na Região de Jundiaí, em São Paulo. 1987. 102p. Tese de Doutoramento. Instituto de Geociências, Universidade de São Paulo.

BOCANEGRA, E.; SILVA JR., G.C. Groundwater exploitation of fractured rocks in South America. Eds.: Krásný J.; Sharp J. IAH Selected Papers, 9, p. 20-32, 2007.

CEZAR, H.S. A Horticultura do Tomate e a Organização do Território em São José de Ubá - Noroeste Fluminense. 2001.135f. Dissertação (Mestrado em Geografia). Instituto de Geociências, Universidade Federal do Rio de Janeiro, Rio de Janeiro.

DANTAS, M. E. Geomorfologia do Estado do Rio de Janeiro - Texto Explicativo do Mapa Geomorfológico do Estado do Rio de Janeiro. Escala 1:50.000. Rio de Janeiro: CPRM, DRM/ RJ, 2001. 60p.
FENZL, N. Introdução à Hidrogeoquímica. Paraná: UFPA, 1988, i, 179p.

FERREIRA, C.R.C.; LA TERRA, E.F.; MENEZES, P.T.L. Modelagem Geofísica para Água Subterrânea em Aquíferos Fissurais em São José de Ubá (RJ). In: WORKSHOP DE INTEGRAÇÃO DE INFORMAÇÕES OBTIDAS NO ÂMBITO DO PROJETO PRODETAB AQÜÍFEROS. 2006. Anais... Rio de Janeiro: Embrapa, 2006. 1 CD-ROM.

GONÇALVES, A.O.; FIDALGO, E.C.C.; BASTOS, C.L.; ABREU, M.B. Caracterização Climática da Bacia do Rio São Domingos. In: WORKSHOP DE INTEGRAÇÃO DE INFORMAÇÕES OBTIDAS NO ÂMBITO DO PROJETO PRODETAB AQÜÍFEROS. 2006. Anais... Rio de Janeiro: Embrapa, 2006. 1 CDROM.

HEILBRON, M.; DUARTE, B.; NOGUEIRA, J.R.; ALMEIDA， C.G.; TUPINAMBÁ, M.; GERALDES, M.; GUIA, C.; MIRANDA, A.W.A.; SILVA FILHO, R.S.; MEDEIROS F.F.F.; MANSUR, K. Geologia da bacia do Rio São Domingos, São José de Ubá, Rio de Janeiro. In: SIMPÓSIO DE GEOLOGIA DO SUDESTE, 2005. Boletim... Niterói, 2005, p.118.

LADEIRA, E.A. Contribuição da Geologia Estrutural à Pesquisa de Águas Subterrâneas em Rochas Cristalinas. Revista Brasileira de Águas Subterrâneas, 7, p. 7-34, 1985.

LUMBRERAS, J.F.; NAIME, U.J.; MOTTA, P.E.F.; PALMIERI, F.; CARVALHO FILHO, A.; BARUQUI, A.M.; CALDERANO, S.B.; FIDALGO, E.C.C.; MOREIRA, D.M. Solos da Bacia Hidrográfica do Rio São Domingos, Município de São José de Ubá e Itaperuna- 
RJ. In: WORKSHOP DE INTEGRAÇÃO DE INFORMAÇÕES OBTIDAS NO ÂMBITO DO PROJETO PRODETAB AQÜÍFEROS. 2006. Anais... Rio de Janeiro: Embrapa, 2006. 1 CDROM.

MENEZES, J.M. Hidrogeoquímica de Aquíferos Fraturados no Noroeste Fluminense: Bacia Hidrográfica do Rio São Domingos - RJ. 2005. 181f. Dissertação (Mestrado em Geologia) Instituto de Geociências, Universidade Federal do Rio de Janeiro, Rio de Janeiro.

MORRIS, B.L., LAWRENCE, A.R.L., CHILTON, P.J.C., ADAMS, B., CALOW R.C. AND KLINCK, B.A. Groundwater and its Susceptibility to Degradation: A Global Assessment of the Problem and Options for Management. Early Warning and Assessment Report Series, RS. 03-3. United Nations Environment Programme, Nairobi, Kenya, 2003.

NEVES, B.B.B, ALBUQUERQUE, J.P.T. Tectônica e Água Subterrânea em Rochas PréCambrianas do Nordeste do Brasil - A Diversidade do Sistema Aquífero. Série Científica Revista do Instituto de Geociências - USP. São Paulo, 4(2):71-90, 2004.

PRADO, R.B.; MENEZES, J.M.; MANSUR, K.L.; MARTINS, A.M.; FREITAS, P.L.; SILVA JUNIOR, G.C.; CARVALHO, L.G.; PIMENTA, T.S.; LIMA, L.A. Parâmetros de Qualidade da Água e sua Relação Espacial com as Fontes de Contaminação Antrópicas e Naturais: Bacia
Hidrográfica do Rio São Domingos - São José de Ubá, RJ. In: SIMPÓSIO BRASILEIRO DE RECURSOS HÍDRICOS, 16., 2005, João Pessoa. Anais... João Pessoa: ABRH, 2005. 1 CD-ROM.

TAYLOR, R.G; HOWARD K.W.F. The influence of Tectonic Setting on the Hydrological Characteristics of Deeply Weathered Terrains: Evidence from Uganda. Journal of Hydrology, 218, p. 44-71, 1999.

TRÖGER, U, CAMPOS, J.E.G., PETERSEN, F., VÖCKLER, H. Groundwater Occurrence in Fractured Metamorphic Rocks - Quality and Quantity, an example from North East Brazil. In: Proc. Intern. Conf. on Groundwater in Fractured Rocks, Prague, Czech Rep. (1): 21-23, 2003.

TUPINAMBÁ, M.; HEILBRON, M.; ALMEIDA, J.; DUARTE, B.; NOGUEIRA, J.R.; GERALDES, M.; ALMEIDA, C.G.; MEDEIROS, F.; MANSUR, K. Base Geológica Da Bacia Do Rio São Domingos, Itaperuna (RJ): Metodologia E Resultados. In: WORKSHOP DE INTEGRAÇÃO DE INFORMAÇÕES OBTIDAS NO ÂMBITO DO PROJETO PRODETAB AQÜÍFEROS. 2006. Anais... Rio de Janeiro: Embrapa, 2006. 1 CDROM.

VIDAL, A. C.; CHANG, H. K. Caracterização Hidroquímica dos Aquíferos da Bacia de Taubaté. Revista Brasileira de Geociências, v. 32. n.2 p.267-276, jun. 2002. 
Hidrogeoquímica de Aquíferos Fraturados: Estudo de Caso na Bacia Hidrográfica do Rio São Domingos, Noroeste do Estado do Rio de Janeiro 